\title{
Green Inefficiency for Regions in China
}

\author{
Tsz-Yi Ke ${ }^{1 *}$, Jin-Li Hu ${ }^{2}$, Wen-Ju Yang ${ }^{3}$ \\ ${ }^{1}$ Department of Economics, Aletheia University, Taipei, Taiwan, China; ${ }^{2}$ Institute of Business and Management, National Chiao \\ Tung University, Taipei, Taiwan, China; ${ }^{3}$ Department of Applied Economics, Yu Da University, Miaoli County, Taiwan, China. \\ Email: tyke@mail.au.edu.tw
}

Received June $9^{\text {th }}$, 2010; revised June 29 $9^{\text {th }}, 2010$; accepted July $9^{\text {th }}, 2010$.

\begin{abstract}
We used the directional output distance function to derive estimates of green inefficiency, shadow prices, and waste costs of three wastes (waste water, waste gas, and solid waste) for thirty regions in China during the 1996-2003 periods. There is an upward trend in green inefficiency in Chinese regions from 1996 to 2003. The green inefficiency score in west area is the lowest but in central and east areas are higher. The costs of wastes have an upward trend in east and central areas but downward trend in west area in the last two observation years.
\end{abstract}

Keywords: Green Inefficiency, Environment Waste, Directional Output Distance Function, Shadow Price, China

\section{Introduction}

In the end of 1980's, China recognized Japan's Industrial development policy which supported Japanese smallsized industries after WWII, and Japan had become the $2^{\text {nd }}$ biggest economic position in the world. Therefore, China introduced this policy to achieve its target of expediting domestic economy development.

The industries of mechanical, electronic, petrolic and chemical have been recognized as the most important industries in order to improve China's economy. Nevertheless, these industries also cause the problems of resources depletion and environment pollution. In the meantime, these industries have been developed quickly, and the conflict has become worst due to the lacking restriction against over resources depletion and environment pollution since 1980's. Thus, China has suffered the three biggest environment wastes which are byproducts accompany with the production of industries: waste water, waste gas, and solid wastes (here after: three wastes).

Water using and management has become a popular issue. The waste water is an important issue in China [1]. Cities in China discharging 10 billion tons of waste water every year. Pesticides in drinking water have also been a problem to the health of a community [2]. In 2005 the chemical firm of Jilin exploded and 100 tons of benzene flowed into Songhua River, then, had the water supply system of Harbin shutdown [3].

The main source of industrial waste gas emission is one of the main sources of air pollution. Most of the existing analyses of air pollution abatement focus on its benefit evaluation [4,5], it possible impacts on economic activities [6], strategies to achieve it [7], or discuss the indices to measure the air quality [8]. Economically efficient abatements of air, solid, and waste pollution still receive relatively not much attention [9].

The investigation of industrial solid waste management in several countries is getting more important recently. For case studies of industrial solid waste and recycling, Casares [10] investigated Asegra in Spain and Donnelly [11] researched the United States and Germany. Moreover, Hogland and Stenis [12] described a method of organization for an industrial solid waste management system in Sweden.

China confronts the three waste problems under the policy of energy-saving. There is no literature taking environment wastes into account to measure national green inefficiency in previously. In this study we try to find out how the environmental problem serious is and provide our suggestion to improve this situation.

\section{Methods}

We will describe the methods of estimating the shadow price, waste cost and evaluating the inefficient of each province in this section.

Suppose that each decision making unit (DMU) uses $N$ inputs to produce $M$ desirable and $J$ undesirable outputs and the output set of production technology can be de- 
fined as:

$$
\mathrm{P}(\mathbf{x})=\{(\mathbf{y}, \mathbf{u}): \mathbf{x} \text { can produce }(\mathbf{y}, \mathbf{u})\}
$$

The undesirable output is the byproduct of the production of the desirable output, we assume that desirable and undesirable outputs are null-joint outputs if

$$
(\mathbf{y}, \mathbf{u}) \in \mathrm{P}(\mathbf{x}) \text {, and } \mathbf{u}=0 \text { then } \mathbf{y}=0
$$

Equation (2) means that if a desirable output is produced in a positive amount then some undesirable outputs also be produced.

Färe and Primont [13] defined the weak disposability of undesirable outputs as follows:

$$
(\mathbf{y}, \mathbf{u}) \in \mathrm{P}(\mathbf{x}) \text {, and } 0 \leq \theta \leq 1 \text { imply }(\theta \mathbf{y}, \theta \mathbf{u}) \in \mathrm{P}(\mathbf{x})
$$

Equation (3) describes that reduction of undesirable outputs can reduce desirable outputs simultaneously while maintaining the same level of inputs.

Färe and Grosskopf [14] defined the directional output distance function as follow:

$$
\begin{aligned}
& \vec{D}_{o}\left(\mathbf{x}, \mathbf{y}, \mathbf{u} ; \mathbf{g}_{\mathbf{y}}, \mathbf{g}_{\mathbf{u}}\right) \\
& =\sup \left\{\beta:\left(\mathbf{y}+\beta \mathbf{g}_{\mathbf{y}}, \mathbf{u}-\beta \mathbf{g}_{\mathbf{u}}\right) \in \mathrm{P}(\mathbf{x})\right\}
\end{aligned}
$$

Equation (5) searches for the largest feasible expansion of desirable output vector $\mathbf{y}$ in the $\mathbf{g}_{\mathbf{y}}$ direction and the largest feasible reduction of undesirable output vector $\boldsymbol{u}$ in the $\mathbf{g}_{\boldsymbol{u}}$ direction. Färe and Grosskopf (2005) provide a relationship between the revenue function and directional distance function. The revenue function is defined as:

$$
\mathrm{R}(\mathbf{x}, \mathbf{p}, \mathbf{r})=\max \{\mathbf{p y}-\mathbf{r u}:(\mathbf{y}, \mathbf{u}) \in \mathrm{P}(\mathbf{x})\}
$$

where $\mathbf{p}=\left(p_{1}, \ldots, p_{M}\right)$ is the desirable output price vector and $\mathbf{r}=\left(r_{1}, \ldots, r_{J}\right)$ is the undesirable output price vector. Equation (5) is the largest feasible revenue that can be obtained from input $\boldsymbol{x}$ and output price vectors $\mathbf{p}$, r.

If the output set is a closed, nonempty convex set then the directional output distance function can be obtained from the revenue function as:

$$
\begin{aligned}
& \vec{D}_{o}\left(\mathbf{x}, \mathbf{y}, \mathbf{u} ; \mathbf{g}_{\mathbf{y}}, \mathbf{g}_{\mathbf{u}}\right) \\
& =\inf _{\mathbf{p}, \mathbf{r}} \mathrm{R}(\mathbf{x}, \mathbf{p}, \mathbf{r})-(\mathbf{p y}-\mathbf{r u}) / \mathbf{p g}_{\mathbf{y}}+\mathbf{r g}_{\mathbf{u}}
\end{aligned}
$$

We can compute the price of the $j$ 'th undesirable output as:

$$
\mathrm{r}_{j}=-\mathrm{p}_{m}\left[\partial \vec{D}_{o}(\bullet) / \partial u_{j}\right] /\left[\partial \vec{D}_{o}(\bullet) / \partial y_{m}\right]
$$

After measuring the shadow price from the above equations, we need alternative method, the directional output distance function, to get the inefficiency value. The linear programming problem for each observation $k$ as follow:

$$
\vec{D}_{O}\left(\mathbf{x}^{k}, \mathbf{u}^{k}, \mathbf{y}^{k} ; \mathbf{g}_{\mathbf{u}}, \mathbf{g}_{\mathbf{y}}\right)=\max _{\beta, z_{1}, \ldots, z_{K}} \beta
$$

s.t.

1) $\sum_{k=1}^{K} z_{k} y_{k m} \geq y_{m}+\beta g_{y m}, m=1, \ldots, M$

2) $\sum_{k=1}^{K} z_{k} u_{k j}=u_{j}-\beta g_{u j}, j=1, \ldots, J$

3) $\sum_{k=1}^{K} z_{k} x_{k n} \leq x_{n}, n=1, \ldots, N$

4) $\sum_{k=1}^{K} z_{k}=1, z_{k} \geq 0, k=1, \ldots, K$

The $\beta$ is the inefficiency value for observation firm. In this study, we use this directional output distance function to derive the estimates of shadow price, measure the inefficient values and take the shadow prices to compute the waste costs.

\section{Results and Discussion}

The major target of an economy is improving living standard in economic development processing. The GDP can be presented as living standard level, so we take GDP as desirable output. In order to increase the GDP that there have to cause some pollutions such as three wastes. We want to increase the GDP but not much pollution. These three wastes are unavoidable when the economy increases the GDP. Therefore, we call three wastes as undesirable outputs.

Data of the desirable output: GDP, be deflated to 1996 values, in each region is collected respectively as stated previously. Real capital stocks in 1996 prices are constructed based on Li's method [15]. ${ }^{1}$ The data of regional labor employment are established from the China Statistical Yearbook. The thirty regions are categorized into three areas. The three areas are the east area (abbreviated as ' $E$ '), the central area (abbreviated as ' $C$ '), and the west area (abbreviated as 'W'). ${ }^{2}$

From China Statistical Yearbook, we establish a dataset for 30 regions in China (27 provinces and 3 munici-

\footnotetext{
${ }^{1}$ The capital stock data are not available in the China Statistical Yearbook. In this study, every regional capital stock in a specific year is calculated by the authors according to this formula: capital stock in the previous year + capital formation in the current year - capital depreciation in the current year. All the nominal values are deflated in 1995 prices before summations and deductions. We find the initial capital stock (capital stock data in 1995) from the research of Li (2003).

${ }^{2}$ According to the Grand Western Development Program, Inner Mongolia and Guangxi are included in west area.
} 
palities) during 1996 to $2003 .{ }^{3}$ There are one desirable output, three undesirable outputs and two inputs in our directional output distance function model. The values of monetary output and input are in 1996 prices.

Descriptive statistics for the outputs and inputs are provided in Table 1. From this table we know that desirable and undesirable outputs satisfy the assumption of null-joint outputs. All of the outputs are greater than zero and hence the directional output distance function can be applied to estimate the inefficiency value.

As Figure 1 illustrates, there is an upward trend in inefficiency of annual average from 1996 to 2003. The best average efficiency occurred in 1996, after which inefficiency trends upward. During the Ninth-Five Plan, the inefficiency value went up in 1997 because of Asian Financial Crisis. The State Council of the People's Republic of China wanted to reduce the damage, they got an idea for increasing the Interior-Need and issued bond of 100 billion RMB to improve the economic situation in 1998. The policy reforms of China took place in this period that changed the inefficiency value across time.

The inefficient value decreased in 2003. We presume that the people prefer the economic growth of China because of the BRIC thesis. It expected the developing countries include Brazil, Russia, India, and China will become the biggest and fastest growing emerging markets.

There is an upward trend in inefficiency in east and west areas from 1996 to 2003. The inefficiency in central area gets down from 2002. Half of the most seriously pollution cities of the world are in the center area. ${ }^{4}$ In average, the green efficiency in center area is the lowest. Relative to center area, there is the most efficient in east area.

We normalized the data, because of convergence problems, by dividing each output and each input by its mean value before estimating Equation (14).

The parameter estimates for the quadratic form of the directional distance function are provided in Table 2. Using these parameters and Equation (11) can measure the shadow prices of three wastes. The opportunity cost can be estimated by shadow price.

Table 3 provides the estimates for the shadow prices and the costs of wastes. The cost is product of shadow price and waste quantity. The average shadow price of waste gas is the highest and the average cost of water waste has the highest level in sample periods. However, the average shadow price and average cost of solid waste are the lowest.

China should pay more attention to waste water which has the highest cost but not the highest shadow price.

${ }^{3}$ Chongqing became a municipality out of Sichuan in 1997 and in this study its outputs and inputs are included in Sichuan.

${ }^{4}$ These cities are Jilin, Shanxi, Henan, and Hubei.
Table 1. Describing statistics for the outputs and inputs. (Base year: 1996).

\begin{tabular}{|c|c|c|c|c|}
\hline Variable & Mean & $\begin{array}{l}\text { Standard } \\
\text { deviation }\end{array}$ & Minimum & Maximum \\
\hline \multicolumn{5}{|l|}{ Desirable Output } \\
\hline $\begin{array}{l}\text { Gross Domestic Product } \\
\text { (million RMB) }\end{array}$ & 235784 & 183387 & 6476 & 780181 \\
\hline \multicolumn{5}{|l|}{ Undesirable Outputs } \\
\hline $\begin{array}{l}\text { Volume of Industrial } \\
\text { Waste Water } \\
\text { (10,000 tons) }\end{array}$ & 64761.54 & 51425.24 & 612.00 & 247524.00 \\
\hline $\begin{array}{l}\text { Volume of Industrial } \\
\text { Waste Gas } \\
(10,000 \text { tons })\end{array}$ & 4680.23 & 3311.35 & 10.00 & 16139.00 \\
\hline $\begin{array}{l}\text { Volume of Industrial } \\
\text { Solid Wastes } \\
(10,000 \text { tons })\end{array}$ & 2707.54 & 2145.65 & 1.00 & 9252.00 \\
\hline \multicolumn{5}{|l|}{ Inputs } \\
\hline $\begin{array}{l}\text { Capital Stock } \\
\text { (million RMB) }\end{array}$ & 1008847 & 838253 & 80454 & 3772421 \\
\hline $\begin{array}{c}\text { Labor } \\
(10,000 \text { persons })\end{array}$ & 2094.84 & 1520.93 & 117.70 & 6307.50 \\
\hline
\end{tabular}

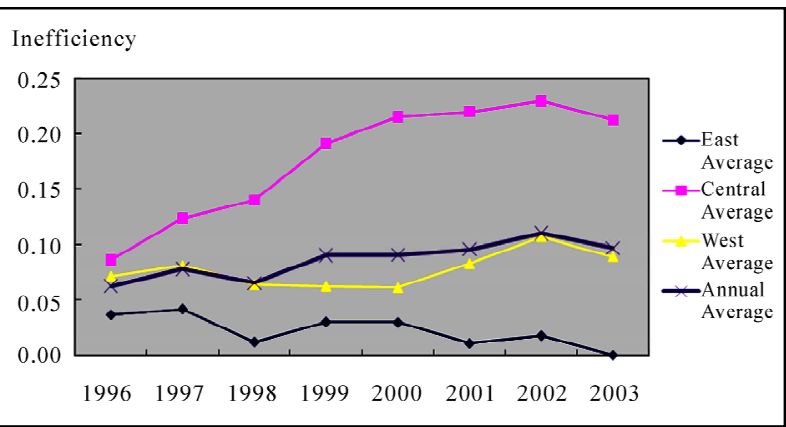

Figure 1. Green inefficiency of annual average.

This implies that the waste water causing high environmental damage but is relatively cheaper to deal with. Some provinces have made several policies to abate the waste water and these policies must be enforced persistently, in order to achieve the long run effects.

Figure 2 to Figure 4 show the total costs of waste water, waste gas and solid waste, respectively. The cost of three kinds of waste in east is the highest but in west is the lowest. From these figures we know that, the most important environmental problem is waste water which has the highest total cost. This is maybe the east area has many downstream rivers flowing into the Pacific Ocean. The east area has hence to pay more cost to deal with waste water.

In order to confront this environmental problem, China built a complete system about water resource management and water pollution control and revise Water Law of the People’s Republic of China in 2002. But it didn’t 
Table 2. Parameter estimates.

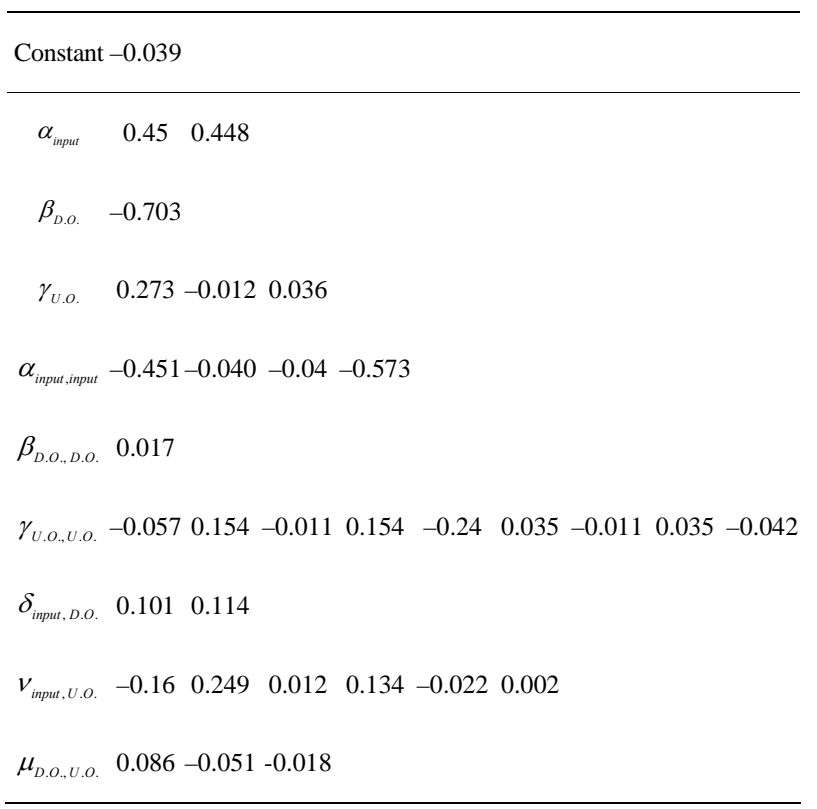

Note: D.O. is desirable output. U.O. is undesirable output.

Table 3. The estimates for the shadow prices and the costs of wastes.

\begin{tabular}{ccccc}
\hline & Mean & $\begin{array}{c}\text { Standard } \\
\text { deviation }\end{array}$ & Minimum & Maximum \\
\hline \multicolumn{5}{c}{ Shadow price } \\
\hline Waste water & 0.835 & 0.618 & 0.248 & 3.671 \\
Waste gas & 1.212 & 1.743 & 0.025 & 12.648 \\
Solid waste & 0.084 & 0.582 & 0.000 & 0.323 \\
\hline & Cost of waste (Million RMB) & \\
\hline Waste water & 717.38 & 1097.98 & 2.35 & 8064.89 \\
Waste gas & 86.01 & 150.73 & 0.00 & 925.58 \\
Solid waste & 2.52 & 3.59 & 0.00 & 21.38 \\
\hline
\end{tabular}

Note: Because $\partial \vec{D}_{o}\left(\mathbf{x}, \mathbf{y}, \mathbf{u} ; \mathbf{g}_{\mathbf{y}}, \mathbf{g}_{\mathbf{u}}\right) / \partial u_{3}=0$, the estimate of shadow price in solid waste term equals zero.

reduce the cost immediately for waste water in 2003. In these figures we find that, the total cost of water waste is the highest. The water problem became a hot issue in every country in the world in this decade. It is costly to deal with the water waste no matter in developing or developed country.

Figure 5 describes the total cost in three wastes in each regional average. We let the province in east area in the right, in west area in the left. The top-six waste cost in regional averages are: Jiangsu (E), Sichuan (W), Guang-

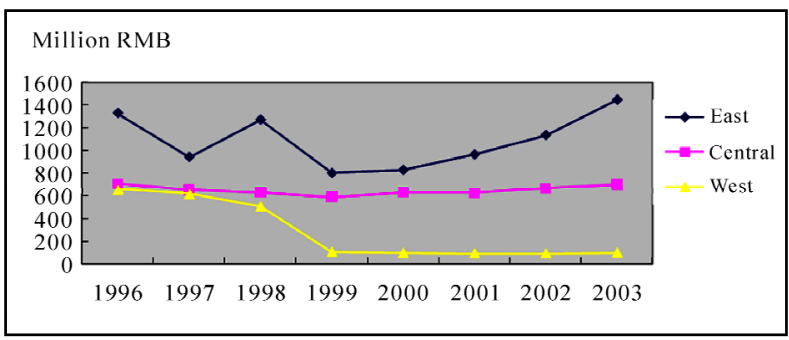

Figure 2. The total cost of waste water.

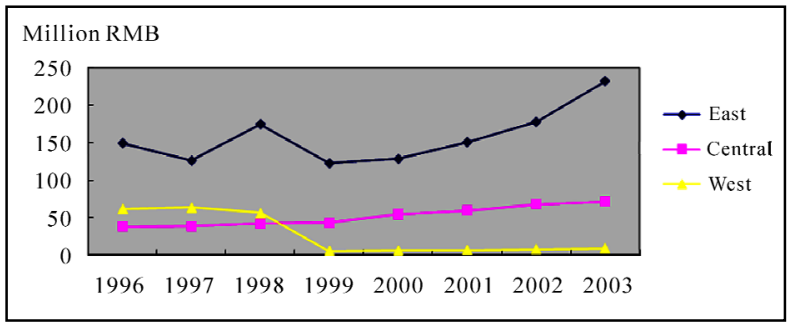

Figure 3. Areas' annual total cost of waste gas.

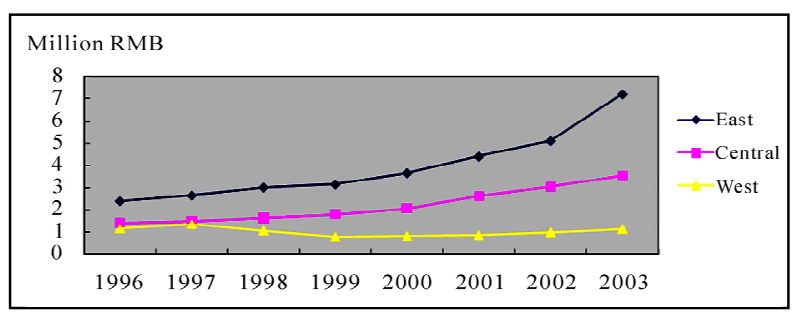

Figure 4. Areas' annual total costs of solid waste.

dong (E), Shandong (E), Henan (C) and Zhejiang (E). Most of east areas have higher waste cost. The lower waste cost in regional averages is: Tibet (W), Qinghai (W), Hainan (E), Ningxia (W), and Xinjiang (W). Most of west areas have lower waste cost. The average shadow price of three kind wastes in Jiangsu and Sichuan with the highest level especial in waste gas. Therefore, there is the seriously waste cost in these provinces. There is the lowest quantity average of three kind wastes especial in waste gas and solid waste, so the lowest waste cost in Tibet.

Figure 6 presents the inefficiency in each regional average. The most efficient regions during the 1996-2003 periods are: Tibet (W), Tianjin (E), Zhejiang (E), Hebei (E) and Shanghai (E). The most inefficient regions during the observation periods as follow: Hubei (C), Henan (C), Hunan (C), Guangdon (E) and Guangxi (W). We find that, most of provinces with higher inefficiency value almost are heavy industry cities.

The inefficiency in the three regions presents a significance difference. ${ }^{5}$ The operating efficiency in east area is superior to other regions obviously. Even east ${ }^{5}$ The Kruskal-Wallis test has significance at the $1 \%$ level. 


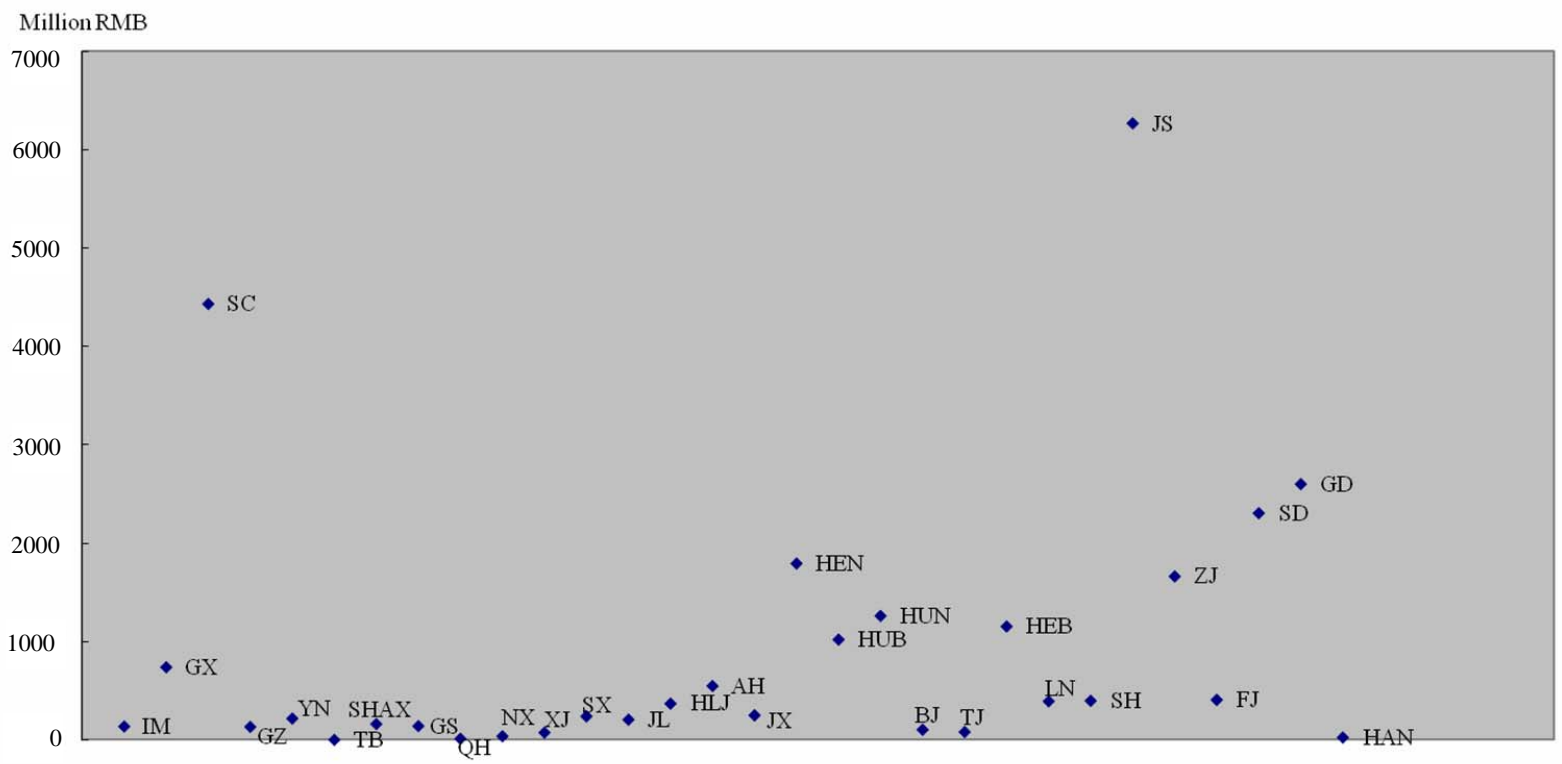

Figure 5. Regional averages of total waste cost.

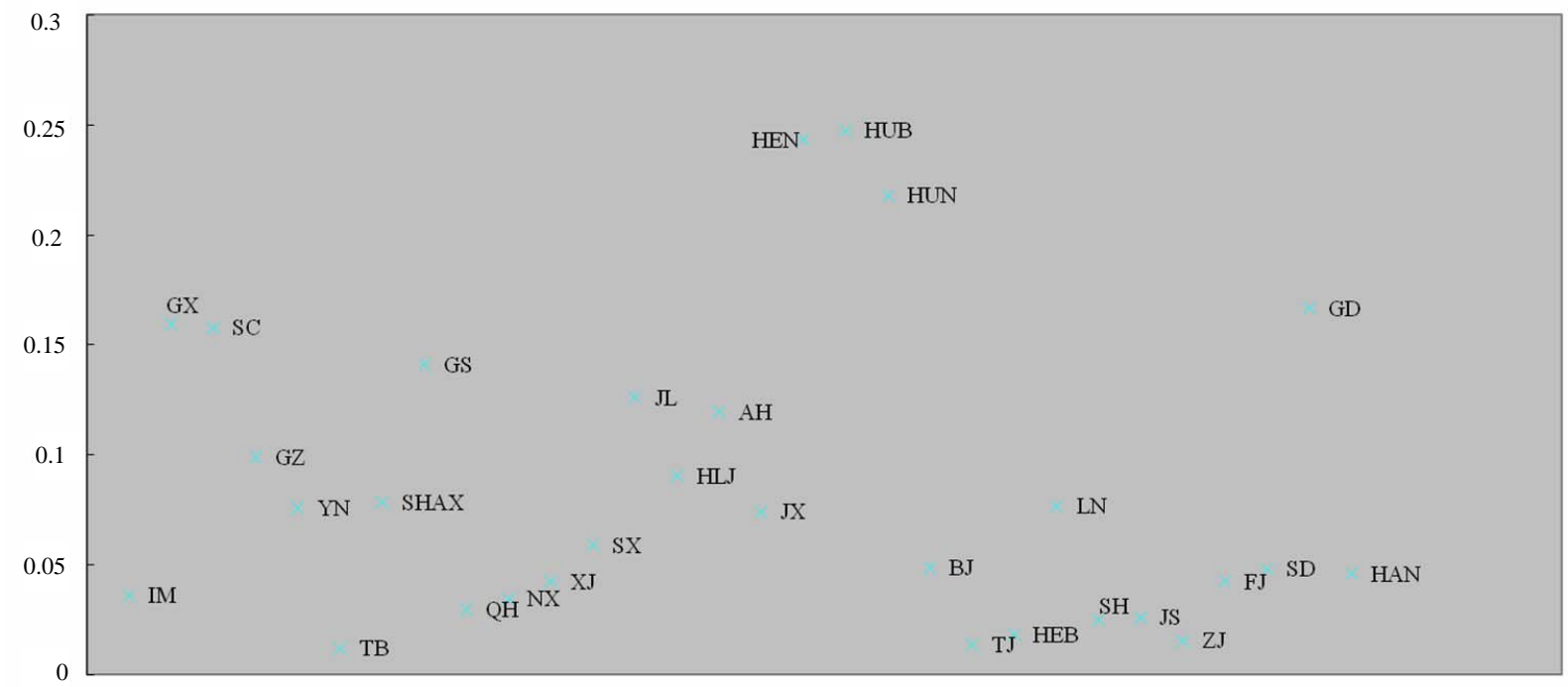

Figure 6. Regional averages of inefficiency.

area has higher waste quantity and cost. Development level plays an important role in our analysis process. The east area has the highest green efficient, because the input and output using is quite well in production procedure rather in other areas.

The inefficiency values of center area are higher then other areas during this study period obviously. The reform policy seems helpful to east area because of the lowest inefficiency value, but harmful to center area because it has constrained generation of three wastes to increase inefficiency value.

\section{Conclusions}

Environmental protection is an important issues in recent. We built an observation set for 30 regions in China during 1996 to 2003. This set concluded one desirable output, three undesirable outputs, and two inputs.

This study used the directional output distance function to derive estimates of production inefficiency, shadow prices, and associated pollution costs of three wastes in China.

Our results indicate that an upward trend in inefficiency from 1996 to 2003. The value of inefficiency in 
west area is the lowest but in central and east areas are higher in related. The costs of three wastes have an upward trend in east and central areas but downward trend in west area in the last two observation years.

We suggest that the China should abate wastes immediately to contract the cost of wastes to get better macroeconomic performance.

\section{REFERENCES}

[1] W. Wu, Y. L. Liu, Q. Zhu, C. Wei and J. Wang, "Remediation of Polluted River Water by Biological Contact Oxidation Process Using Two Types of Carriers," International Journal of Environment and Pollution, Vol. 38, No. 3, 2009, pp. 223-234.

[2] M. Vighi and E. Funari, "Pesticide Risk in Groundwater," Lewis Publishers, Boca Raton, 1995.

[3] W. Chen, "View from China: Stakeholder Capitalism: In an Era of Unchecked Growth, China's CFOs Could Use a Lesson in Stakeholder Capitalism," CFO Magazine, 15 March 2006.

[4] S. Kumar and D. N. Rao, "Valuing the Benefits of Air Pollution Abatement Using a Health Production Function: A Case Study of Panipat Thermal Power Station,” Environmental and Resource Economics, Vol. 20, No. 2, 2001, pp. 91-102.

[5] E. Mentzakis and D. Delfino, "Effects of Air Pollution and Meteorological Parameters on Human Health in the City of Athens, Greece," International Journal of Environment and Pollution, Vol. 40, No. 1-2, 2010, pp. 210-225.

[6] O. Kiuila, "Economic Modeling of Sulfur Regulations in Poland," International Journal of Environment and Pollution, Vol. 19, No. 4, 2003, pp. 390-402.
[7] L. Shi, L. Xing, G. Lu and J. Zou, "Evaluation of Ratiobnal Sulphur Dioxide Abatement in China," International Journal of Environment and Pollution, Vol. 35, No. 1, 2008, pp. 42-57.

[8] A. K. Gupta, R. S. Patil and S. K. Gupta, “A Comparison of Air Quality Indices for a Port and Harbor Region in India,” International Journal of Environment and Pollution, Vol. 26, No. 4, 2006, pp. 313-326.

[9] J. L. Hu, "Efficient Air Pollution Abatement for Regions in China," International Journal of Sustainable Development and World Ecology, Vol. 13, No. 4, 2006, pp. 327340.

[10] M. L. Casares, N. Ulierte, A. Mataran, A. Ramos and M. Zamorano, "Solid Industrial Wastes and their Management in Asegra (Granada, Spain),” Waste Management, Vol. 25, No. 10, 2005, pp. 1075-1082.

[11] J. E. Donnelly, "Numbers Never Lie, but What do They Say: A Comparative Look at Municipal Solid Waste Recycling in the United States and Germany," Georgetown International Environment Law Review, Vol. 15, No. 1, 2002, pp. 29-52.

[12] W. Hogland and J. Stenis, “Assessment and System Analysis of Industrial Waste Management,” Waste Manage, Vol. 20, No. 7, 2000, pp. 537-543.

[13] R. Färe and D. Primont, "Multi-Output Production and Duality: Theory and Applications," Kluwer-Academic Publishers, Boston, 1995.

[14] R. Färe and S. Grosskopf, "New Directions: Efficiency and Productivity,” Kluwer-Academic Publishers, Boston, 2005.

[15] K. W. Li, “China's Capital and Productivity Measurement Using Financial Resources,” Economic Growth Center, Yale University, 2003. http://www.econ.yale.edu / egcenter/research.htm 


\section{Appendix}

Abbreviation in provinces.

\begin{tabular}{|c|c|c|}
\hline Province & Abbreviation & Area \\
\hline Beijing & BJ & $\mathbf{E}$ \\
\hline Tianjin & $\mathbf{T J}$ & $\mathbf{E}$ \\
\hline Hebei & HEB & $\mathbf{E}$ \\
\hline Shanxi & SX & C \\
\hline Inner Mongolia & IM & W \\
\hline Liaoning & $\mathbf{L N}$ & $\mathbf{E}$ \\
\hline Jilin & $\mathbf{J L}$ & C \\
\hline Heilongjiang & HLJ & C \\
\hline Shanghai & SH & $\mathbf{E}$ \\
\hline Jiangsu & JS & $\mathbf{E}$ \\
\hline Zhejiang & ZJ & $\mathbf{E}$ \\
\hline Anhui & AH & C \\
\hline Fujian & FJ & $\mathbf{E}$ \\
\hline Jiangxi & $\mathbf{J X}$ & C \\
\hline Shandong & SD & $\mathbf{E}$ \\
\hline Henan & HEN & C \\
\hline Hubei & HUB & C \\
\hline Hunan & HUN & C \\
\hline Guangdong & GD & $\mathbf{E}$ \\
\hline Guangxi & GX & $\mathrm{W}$ \\
\hline Hainan & HAN & $\mathbf{E}$ \\
\hline Sichuan & SC & $\mathbf{W}$ \\
\hline Guizhou & GZ & $\mathbf{W}$ \\
\hline Yunnan & $\mathbf{Y N}$ & $\mathbf{W}$ \\
\hline Tibet & TB & $\mathbf{W}$ \\
\hline Shaanxi & SHAX & $\mathbf{W}$ \\
\hline Gansu & GS & $\mathbf{W}$ \\
\hline Qinghai & QH & $\mathbf{W}$ \\
\hline Ningxia & $\mathbf{N X}$ & $\mathbf{W}$ \\
\hline Xinjiang & $\mathbf{X J}$ & $\mathbf{W}$ \\
\hline
\end{tabular}

